\title{
Jean-Jacques Vincensini et Claudio Galderisi (dir.), Le Récit idyllique. Aux sources du roman moderne
}

G. Matteo Roccati

\section{CpenEdition}

\section{Journals}

Édition électronique

URL : http://journals.openedition.org/studifrancesi/3639

DOI : 10.4000/studifrancesi.3639

ISSN : 2427-5856

Éditeur

Rosenberg \& Sellier

\section{Édition imprimée}

Date de publication : 1 décembre 2012

Pagination : 541

ISSN : 0039-2944

\section{Référence électronique}

G. Matteo Roccati, « Jean-Jacques Vincensini et Claudio Galderisi (dir.), Le Récit idyllique. Aux sources du roman moderne », Studi Francesi [En ligne], 168 (LVI | III) | 2012, mis en ligne le 30 novembre 2015, consulté le 06 mars 2021. URL : http://journals.openedition.org/studifrancesi/3639 ; DOI : https:// doi.org/10.4000/studifrancesi.3639

Ce document a été généré automatiquement le 6 mars 2021.

\section{cc) (†) $\ominus$}

Studi Francesi è distribuita con Licenza Creative Commons Attribuzione - Non commerciale - Non opere derivate 4.0 Internazionale. 


\title{
Jean-Jacques Vincensini et Claudio Galderisi (dir.), Le Récit idyllique. Aux sources du roman moderne
}

\author{
G. Matteo Roccati
}

\section{RÉFÉRENCE}

JEAN-JACQUES VINCENSINI et CLAUDIO GALDERISI (dir.), Le Récit idyllique. Aux sources du roman moderne, Paris, Editions Classiques Garnier, 2009 («Recherches littéraires médiévales», 2), pp. 214.

1 Entre cadre pastoral et récit des amours contrariées de deux jeunes gens, l'Introduction par J.-J. Vincensini parcourt les thèmes qui relèvent du genre en essayant de cerner sa signification esthétique. Le volume rassemble ensuite dix études et est organisé en deux parties, la première consacrée au "genre?», la deuxième à certaines œuvres. Claudio GALDERISI, Idylle versus "fin'amor"? De l'«amor de lonh» au mariage, pp. 29-44, se demande «si le récit idyllique est à l'origine d'une nouvelle poétique romanesque qui s'oppose à la fois au lyrisme occitan et au roman courtois» (p. 31). Giovanna ANGELI, Enfants, frères, amants: les ambiguités de l'idylle de «Pyrame et Thisbé» à «Aucassin et Nicolette», pp. 45-58, traque dans les textes «l'ombre de l'inceste» (p. 54). Friedrich wolfzettel, Le paradis retrouvé: pour une typologie du roman idyllique, pp.59-77, distingue les deux types romanesques, arthurien et idyllique: à la temporalité "progressive et dialectique» (p.63) du premier il oppose la négation du temps du deuxième, au sens où, dans le récit, «il s'agit de tout ramener au statu quo» (p. 63), c'est-à-dire de rétablir le paradis perdu; ce modèle mythique évolue toutefois rapidement vers le roman d'amour tout court. Anna Maria BABBI, Destins d'amants: la réception de «Paris et Vienne» et «Pierre de Provence et la Belle Maguelonne» dans la littérature européenne, pp.153-163, donne un aperçu des traductions et des impressions des deux romans. Sergio CAPPELLO, Réception et réécritures 
du roman idyllique au XVI e siècle, pp.179-191, suit l'évolution littéraire du modèle idyllique à travers l'examen des impressions de la Renaissance.

2 Les autres études concernent des textes particuliers: médiévaux (Jean-Jacques VINCENSINI, Le raffinement de la souffrance «idyllique». Sur «Pierre de Provence et la Belle Maguelonne», pp. 79-99; Marion UHLIG, L'idylle en péril: amour et inconduite dans «L'Escoufle» de Jean Renart, pp. 127-151), antique (Romain BRETHES, Comment lire «Les Pastorales» de Longus? Le cas d'un roman idyllique sophistiqué, pp. 103-125) ou plus récents (François PIAZZA, Les jeux du hasard et du destin: Idylle et roman chevaleresque dans le "Roland Furieux» (1450-1550), pp.165-178; Bruno GARNIER, La Fontaine sourcier de l'idylle. Les amours de Pyrame et Thisbé dans «Les Filles de Minée», pp. 193-201). Le volume comporte l'Index des noms et l'Index des cuvres. 